\title{
6 Before meaning: reproduction and consumption of terra sigillata and 'Rhenish' wares in Essex (2nd-3rd centuries AD)
}

The trajectory of the category of 2 nd century Lezoux sigillata continued beyond distribution and exchange as discussed in chapter 4. This final chapter explores how sigillata's definition as a category set further possibilities for how its production knowledge could be transferred, and how the pots could be consumed. The previous chapter has introduced the importance of the relation between sigillata and 'Rhenish' wares, as well as the notion that not every product was defined as a homogeneous and bounded category. Third century Trier 'Rhenish' wares, for example, were not the same always and everywhere. Instead, they were characterised by variability, but also by a defining relation to the locality and physicality of the production place and process. This chapter will contrast how the 'categorical' 2 nd century Central Gaulish sigillata and the 'rooted' 3rd century Trier 'Rhenish' wares shaped their respective possibilities for reproduction and consumption.

\section{I C ON DITION S F R (RE) P R O D U C T I O N}

One way in which the trajectories of sigillata and 'Rhenish' wares developed was through the spread of the knowledge and standards of their production. How did their respective definition in production impinge on the process of technological transfer? The logical chronological and spatial extension of the previous chapters is to take into account multiplication to and in Britain, where local ceramic fine ware production appeared alongside imports around the middle of the 2nd century AD. Moreover, Britain offers a well-researched case study yielding a number of suitable assemblages.

\section{I. I (RE) PRODUCING A CATEGORY}

The previous chapter discussed how transferring the production of sigillata as a category from Central Gaul to Trier required a lot of effort. Its definition by a standardized package of traits and a sharp boundary needed constant reaffirmation in order to be maintained. ${ }^{667}$ In the case of the sigillata category travelling from Central Gaul to Trier, this maintenance work was assured through pairing the sigillata production sequence with that of its 'Other', 'Rhenish' wares. How did this need for intensive maintenance work affect the overall production landscape of sigillata?

The lack of sigillata production in Britain has often been remarked upon, as this contradicts the expectations of 'rational' economic action. Indeed, given the huge amounts of sigillata being transported to and consumed in Britain, it is notable that sigillata production did not take off in the province itself. An attempt was made to install sigillata production at Colchester around AD 155, but this was not very successful. ${ }^{668}$ In light of the limited production output comparatively large numbers of wasters were

667 'Immutable mobiles': Latour 1988; Law 1986; Law/Singleton 2005.

668 Tyers 1996, 114-116. The case of the 'Aldgate-Pulborough' potter, with decorative schemes derived from Central Gaulish products (Marsh 1979; Simpson 1952; Webster 1975), will not be discussed here, as too little evidence is available. 
retrieved, either overfired, or - more rare on the Continent - underfired ${ }^{669}$ As such the short-lived fate of sigillata production at Colchester (end date around AD 180) tends to be ascribed to deficiencies of the local clay, and problems with firing. ${ }^{670}$ Again, the search for a cause in retrospective approaches cannot but point to external actors: the clays were no good, or the potters did not master their crafts.

Nevertheless, there is evidence that the potters at Colchester came in with skilled expertise in East Gaulish sigillata production. Dies from the potters Lipuca and Miccio can be traced from the Gaulish sites of La Madeleine and Sinzig to Colchester, probably indicating their consecutive workplaces. ${ }^{671}$ Based on stylistic affinities of moulds, it is generally held that a first phase of sigillata production at Sinzig was indeed brought about by a move from La Madeleine. ${ }^{672}$ Minuso ii's stamp distribution in turn indicates successive activities at Trier and Colchester ${ }^{673}$, and it would seem likely that this transmission too occurred via Sinzig, where a second wave of new figure-types has been related to potters from Werkstatt $I$ at Trier. ${ }^{674}$ Given the fact that these potters had gained considerable experience in producing sigillata, and in adapting their skills and product to different circumstances at different production sites, it is all the more curious that they would have been 'unable' to do so at Colchester.

Where does sigillata itself come in? Can the counterintuitive absence of sigillata production in Britain be explained better when placed (non-retrospectively) at the end of sigillata's historical trajectory? We have seen that the early sigillata production at Trier did not conform to the parameters set by the Lezoux category. ${ }^{675}$ The package of traits was loosened, and the presence of one trait no longer implied the entire package: for example, shiny slips could be achieved without using calcareous clays. Arguably the lack of these strictly defining 'either/or' parameters facilitated the multiplication of production sites in East Gaul: a wider latitude of variation and less rigid external boundaries within the production sequence assured a greater adaptability of East Gaulish sigillata to varying skills, clays, infrastructure, etc. This resulted in a mosaic of production sites as opposed to the more centralized Central Gaulish sigillata production landscape in the second half of the 2nd century.

Colchester sigillata production fits within a similar multiplication to Britain of this East Gaulish sigillata 'template' as initially observed at Trier: forms covered the contemporary East Gaulish repertoire, and wasters and moulds were associated with a single circular kiln ${ }^{676}$, which showed technical similarities to some East Gaulish sigillata kilns (e.g. Heiligenberg) ${ }^{677}$. Moreover, well-fired Colchester sigillata is often difficult to distinguish from imported 2nd century East Gaulish sigillata, with a red-brown fabric and (yellow-)brown slip. ${ }^{678}$ Moreover, Colchester sigillata production was closely associated with colourcoated wares, as illustrated by fragments of a barrel-shaped sigillata beaker, a form 'scarcely' known in sigillata outside Colchester, but common in colour-coated wares on the Continent. ${ }^{679}$ Similarly, compared to East Gaulish decorative canons ${ }^{680}$, hunt scenes typical for colour-coated wares abound on Colchester sigillata moulds, with running animals (especially deer and dogs) ${ }^{681}$ and few human figures. This selective appropriation parallels the contemporary popularity of colour-coated 'hunt cups' (below), and was possible due to the loose East Gaulish sigillata template, which was not kept clearly separate from other production sequences.

But in Britain this fairly adaptable definition of sigillata encountered a rather different template in the mass of 2nd century imported Lezoux products. The latter had been defined as 'categories' in production,

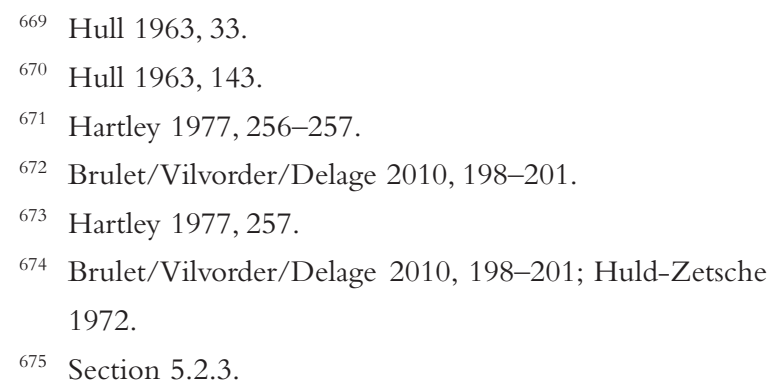

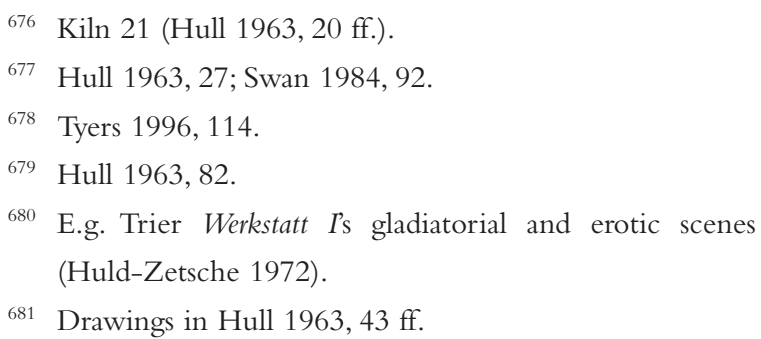


which, as discussed earlier, made them amenable to comparison based on their individual traits, without challenging the constituent relations between these traits. Questions such as 'how shiny is the shiny slip'?, or 'which clay bed yields the best calcareous clay?' were promoted, while the fact that shiny slip always implies calcareous clays went unquestioned. Colchester sigillata was drawn into this comparison because of the visual (and, to a lesser extent, technical) similarities with these Central Gaulish imports. ${ }^{62}$ But variability and adaptability rather than a fixed package of traits were constitutive of Colchester sigillata, which thus did not lend itself to a comparison of traits.

Colchester became a point of encounter and tension between different definitions of a 'single' thing, sigillata. The two different sigillata templates would have set parameters of evaluation that would have been incompatible. ${ }^{683}$ Colchester pots whose production practices were 'a bit like sigillata' but also 'a bit like colour-coated wares' would have been placed firmly outside of the either/or category boundary set by the imported Lezoux sigillata, despite their broadly similar appearance. Things, skills and possibilities that would have gone unquestioned at Colchester now became the subject of doubt. Incompatibility between the two definitions of sigillata production was exacerbated by the fact that the Lezoux sigillata-as-category came in as a finished product, far removed from the contingency of its production. Colchester potters were faced with the finished product, the commodity, without being able to link this to a particular production sequence and specific embodied skills, which would have been easier to 'compare to'.

It is not difficult to imagine how the overlap between practices associated with colour-coated wares and sigillata at Colchester could not be aligned with the category's binary standards (a pot could not be 'a bit sigillata' and 'a bit colour-coated'), and how the adaptation of firing and technique to local clays became a less straightforward exercise than it had been in East Gaul. This is a case where the definition of sigillata as a category in production at Lezoux continued to cast its spell on the subsequent trajectory of the product (as it had arrived in Britain). The maintenance of rigid parameters for the category in production entailed possibilities of comparison and measurement that in turn compromised other production sequences and their products (Colchester sigillata).

Traditionally, historical explanations of the location of terra sigillata production sites point to external agents, such as migrating craftsmen, environmental constraints, and economic considerations. ${ }^{684}$ But these are always partial, and bound to remain elusive. Instead, part of the explanation why sigillata production at Colchester did not take off is to be found in the misalignment of two differently articulated trajectories: one of (Lezoux) sigillata defined as a category, with the particular conditions for action this created; and one of (East Gaulish) fine wares defined as skilled and flexible production practices, which struggled to fit its products in an either/or categorical frame. Lezoux sigillata's definition as a category itself thwarted reproduction at Colchester, and resulted in a fairly centralized production landscape. Yet again, we find sigillata as a history-maker.

\section{I. 2(RE) PRODUCING A SKILLED PRODUCTION PROCES}

Despite the issues with sigillata production, local production of dark-coloured beakers and flagons flourished in Britain from the mid 2nd century onwards. Chronologically, this overlapped with the peak period of (Central Gaulish) sigillata supply, and coincided with the start of 'Rhenish' ware production at Trier. The two important production areas were Colchester (from ca. AD 120) ${ }^{655}$ and the Nene Valley

682 This would not have been the case for East Gaulish sigillata production sequences as imports of Central Gaulish sigillata in East Gaul were scarce.

683 Cf. Pickering 1984 on incommensurability between different scientific traditions.
684 Van Oyen 2015d, 287-288.

685 The small-scale pre-Flavian colour-coated production at Colchester (in response to Lyon ware imports) had no connection with the 2nd century phenomenon:Anderson 1980, 35; Symonds/Wade 1999, 233-237; Tyers 1996, 168. 
(centred on Water Newton, a former Roman fort which became the small town Durobrivae; from ca. mid 2nd century). The very fact that the products of these sources are often confused ${ }^{686}$ attests both to their similarity and to their lack of internal cohesion.

The earlier start date of Colchester colour-coated wares ${ }^{67}$ places them in a different context: Central Gaulish 'Rhenish' ware production had not yet properly taken off ${ }^{688}$, and the production of Trier (and East Gaulish) sigillata was not yet modelled after the Central Gaulish category. Firstly, a link to Rhineland colour-coated ceramics can be discerned. The colour-coated repertoire consisted mainly of beakers (especially Cam 391, a bag-shaped beaker with cornice rim) - many similar to contemporary Cologne and Lower Rhineland products - alongside flagons and so-called 'Castor boxes'. Decoration included roughcasting, rouletting, and barbotine; the latter sometimes depicted hunt scenes inspired by Cologne hunt cups, but with subdivided panels and more elongated animals. Secondly, a considerable degree of variation was maintained, for example in firing, resulting in differences between fabrics and a colourcoat veering from matt red/brown to dark grey/black. ${ }^{699}$ Finally, as mentioned above, the production sequences of sigillata and colour-coated wares were closely interrelated at Colchester. This included occasional overlap in exterior reddish colour, and sporadic examples of a colour-coated beaker form (Anderson Form 5) ${ }^{690}$ executed 'as sigillata'. Hull also mentions a greyish-chocolate colour-coat beaker Cam 391 with traces of barbotine and an impression of a sigillata stamp (ACCEPTVSF) just below the rim. ${ }^{61}$ This is proof that the same potter(s) and workshop(s) produced sigillata and colour-coated wares, and attests to these products' practical and conceptual linkage. Whether by mistake or not, it was possible to extend the 'sigillata' practice of stamping to colour-coated wares; such traits were not seen as belonging exclusively to a sigillata package, as was the case at Lezoux.

The colour-coated wares lasted longer and reached more widely than Colchester sigillata. ${ }^{692}$ While the latter struggled by being drawn into a comparison with the imported sigillata category, colour-coated wares could thrive as an appropriation of a Lower Rhineland craft tradition. Definition of Colchester colour-coated production was centred on the embodied skills and expertise ('this is how we do it'), not on the finished product ('this is how it is done'), as with Central Gaulish sigillata. The 'sigillata' name stamp 'Acceptus f[ecit]' occurring on a colour-coated beaker exemplifies the personalized nature of this tradition, and thus performed a different role from the 2nd century sigillata stamps. This is not unlike the 'rooted' definition of 3rd century Trier 'Rhenish' wares, with the exception that the site of Trier itself, its clay sources, its geography, and its institutional links proved crucial in that case. Moreover, Colchester colour-coated wares were not as much cast as sigillata's 'Other' (as 'Rhenish' wares had been in 2nd century Lezoux), but genealogically linked to them by a skilled set of expertise, which made them less reliant on the fate of sigillata production.

As Colchester colour-coated wares had taken off, several potters in the Nene Valley followed. Local coarse-ware production was established from the later 1st century onwards ${ }^{693}$, and continued after the onset of colour-coated production (which took up about one third of the total output ${ }^{694}$ ). Much like observed for Colchester, Nene Valley colour-coated production can be characterized as variable and personalized. The kilns were distributed alongside the river Nene, and organisational links can be posited to both the town of Durobrivae and its suburbs, and the interspersed remains of substantial domestic

\footnotetext{
686 Tyers 1996, 168.

687 Anderson 1980, 35-38; Symonds/Wade 1999, 267-278; Tyers 1996, 167-168.

${ }^{688}$ Central Gaulish colour-coated production had been tailing off since the early 2 nd century.

689 Tyers 1996, 167.

690 Anderson 1980, 36.
}

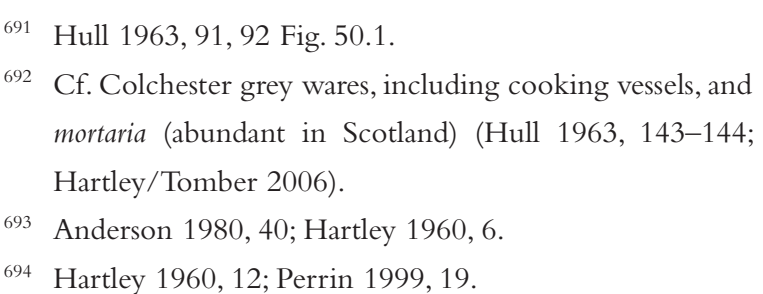


structures ${ }^{695}$ Hence it is possible that investment in this mosaic-like production landscape was fragmented and occurred via multiple channels. Here too considerable latitude of variation was allowed for in fabric (white to orange-brown or greyish) and coating (matt dark brown to black, often mottled). The latter had a specially prepared iron-rich composition, in order to obtain a blackish (reducing firing) or brownish (oxidizing firing) appearance, in line with the contemporary vogue for beaker forms (cf. 'Rhenish' wares). Potters' fingerprints feature commonly on the slip, parading personalized ties. Marked structural differences existed between consecutive kilns. ${ }^{696}$ Hartley notes that 'there is little to suggest that the choice of kiln type was determined by the class of pottery to be fired' ${ }^{697}$, and both mixed and single-product kiln loads have been found in situ. ${ }^{698}$

This variability allowed for links to be established with various other products and production practices. Nene Valley kilns show similarities with 'the kilns in use in the smaller East-Gaulish samian factories ${ }^{699}$ and more generally kilns used in the Rhineland; more than with examples at Colchester. A similar pattern emerges based on the decorative techniques: whereas roughcasting was prominent among Colchester colour-coated wares, it is almost unknown on Nene Valley products. Nevertheless, the use of rouletting and barbotine was shared between both centres. Barbotine was variably applied under (cf. Lezoux 'Rhenish' wares and Cologne colour-coated wares) or over (cf. Trier 'Rhenish' wares) the slip, and it is possible that this indicates a chronological difference ${ }^{700}$, reflecting successive sources of influence. Barbotine hunt scenes recall 2nd century Cologne beakers and contemporary Colchester products. The earliest of these scenes were applied on bag-shaped pedestal beakers ${ }^{701}$ common in the Central Gaulish 'Rhenish' ware repertoire (Bet 310), even though hunt scenes were only rarely present on Central Gaul-

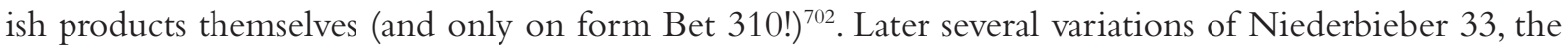
emblematic beaker for Trier 'Rhenish' ware production, were used (cf. Fig. 5.5). All the while, Castor boxes again tied into the Colchester repertoire instead of continental sources.

Around the beginning of the 3rd century AD, elements of sigillata production were adopted in the Nene Valley. Bowls (Drag. 37 and 38), dishes (especially Drag. 31) and flagons, sometimes stamped, were added to the repertoire ${ }^{703}$, but were "based on the late East Gaulish variants, and not on the normal Central Gaulish type, which was always more common in Britain ${ }^{704}$. Moreover, moulds were crude and often incised ${ }^{705}$ rather than figure-stamped. The reason for these sudden adoptions tends to be sought in the waning $^{706}$ of sigillata supply to Britain. But the products' trajectories again shed more light on this issue. Both the chronology (3rd century) and the origins (East Gaul instead of Central Gaul) of these adoptions meant that they were played out in relation to a 'sigillata' that was no longer cast as a homogeneous category. As a consequence, its package of traits was no longer fully defining and bounded, and it became easier to select and appropriate separate elements from this package, without this entailing adoption of the entire package (e.g. either red colour or not; red and sintered slips). Moreover, colour-coated wares' incorporation of some sigillata traits would have been different enough to the imported Central Gaulish sigillata so as to escape direct comparison with them. ${ }^{707}$

695 Mosaics and baths have been signalled (Hartley 1960,

7; Mackreth 1984; Perrin 1999; Upex 2001), but it is unclear whether these structures served agricultural functions too.

${ }^{696}$ Hartley 1960, 9-17.

697 Hartley 1960, 16.

698 Perrin 1999, 19 and passim.

699 Hartley 1960, 17; Swan 1984, 95-97.

700 Hartley 1960, 20; Howe/Perrin/Mackreth 1981, 8; Perrin 1999, $89 \mathrm{ff}$.

701 Howe/Perrin/Mackreth 1981, 8; Perrin 1999, 89 ff.
702 Brulet/Vilvorder/Delage 2010, 346-347.

703 Tyers 1996, 173; Hartley 1960, 20; Perrin 1999, 102.

704 Hartley 1960, 21.

705 Anderson 1980, 39.

706 Sigillata supply to Britain became infrequent but did not stop by the early 3rd century AD (Willis 2005, 6.7 contra Anderson 1980, 41).

707 A similar narrative works for Oxfordshire (from ca. AD 240) and Hadham red slipped wares (from mid 3rd century AD). Cf. 'derivatives' in East Gaul: Brulet/Bocquet/ Laduron 1994. 
To summarize, just like Colchester colour-coated wares, their Nene Valley counterparts were characterized by significant latitude of variation. Moreover, they maintained relations with various production landscapes: the Lower Rhineland and Cologne (hunt scenes), Central Gaulish 'Rhenish' wares (form Bet 310), Trier 'Rhenish' wares (white barbotine applied over slip), and East Gaulish sigillata (form Drag. 36, 3 rd century). Elements from these sources were selectively appropriated and expanded. For example, hunt scenes appeared on pedestal beakers, a combination introduced but not widely developed at Lezoux, in contrast to the different beaker forms used for the more numerous hunt cups at Cologne and Colchester. As was the case for Colchester, there was not so much a transferral of a product, but of a set of embodied skills that could be recombined.

Again, this seemingly trivial observation has important consequences for historical interpretation. A dominant narrative in relation to the 'success' or 'failure' of various ceramic industries is that of rational economic competition. ${ }^{708}$ Fulford ascribed the different fate of sigillata and colour-coated production in Britain to a greater demand for the latter ${ }^{709}$, but there is no evidence to support this claim, on the contrary. ${ }^{710}$ Distance from competitors on the Continent has also been invoked. ${ }^{711}$ But why were Colchester colour-coated wares more long-lived than Colchester sigillata, despite their equal geographical position?

The concept of competition begs remodelling, from blank verb insertable in between any two 'actors' (A competes with B) to a specific kind of relation that is only made possible by 'actors' defined in a certain way (A has to be comparable to B). When analysing competition, we need to ask which traits are being compared, based on which parameters. ${ }^{712}$ Colour-coated wares were not defined as categories with clearly defined attributes that could be measured as performing 'better' or 'worse' in relation to each other. Instead, historical narratives building on colour-coated wares should put more emphasis on craft knowledge and potters' identities in their search for causal factors. This is not to say that 2nd century terra sigillata production at Lezoux was not skilled, quite the contrary, as previous chapters testify. But whereas this skilled engagement between pot, potter, and community of craftsmen was pushed to the background of how sigillata was defined (and the firing lists showed how this was achieved), it remained at the core of colour-coated wares' definition, and thus of their historical role.

\subsection{NICHES IN CONSUMPTION}

\subsection{A N ESSEX CASE S T U DY}

A final way in which trajectories continue is through consumption. How did sigillata and 'Rhenish' wares shape their own possibilities for consumption? A potential study area to examine consumption practices needs to span the period from at least the middle of the 2nd century until the later 3rd century and yield the full gamut of products under study. Britain satisfies these criteria. More specifically, the following discussion will focus on what is now Essex, for two reasons: firstly, it is one of the most evenly researched and best published regions of Roman Britain ${ }^{713}$, and secondly, continental imports (in particular East Gaulish sigillata ${ }^{714}$ and 'Rhenish' wares) became scarcer further westwards.

708 Cf. Picon 2002a on Lezoux.

709 Fulford 1977, 307-309.

710 Pollard 1988, 82 on Kent.

711 Fulford 1977, 309.

712 Cf. Gerrard 2002; Millett/Graham 1986, 90-91; Millett 1990, 172. It is also worth asking whether the long waves described by Going (1992) could be in part due to different product definitions: for example, a log phase with rapid typological change (and a resulting fine-grained chronology), as in the sigillata peak periods, relies on the possibility of perceptible linear change in the product, and thus on its definition as a discrete ('changeable') entity at any given stage.

713 E.g. Perring 2002.

714 Willis 2005, 6.7. 
Sherd count

\begin{tabular}{|l|l:l|}
\hline site & CG RW & EG RW \\
\hline Colchester & 77 & 737 \\
\hdashline Chelmsford & 36 & 5 \\
\hdashline Ivy Chimneys, Witham & 4 & 58 \\
\hdashline Chignall & 4 & 12 \\
\hdashline Rivenhall & 7 & \\
\hdashline Coggeshall & 1 & \\
\hdashline Rayne & & 2 \\
\hline
\end{tabular}

Table 6.1. Sherd count of Central Gaulish (CG RW) and East Gaulish (EG RW) 'Rhenish' wares at published and quantified sites in Essex. Quantification at site level, except for Rivenhall (single stratified assemblage). Data based on site reports listed in Perring 2002, 73-79.

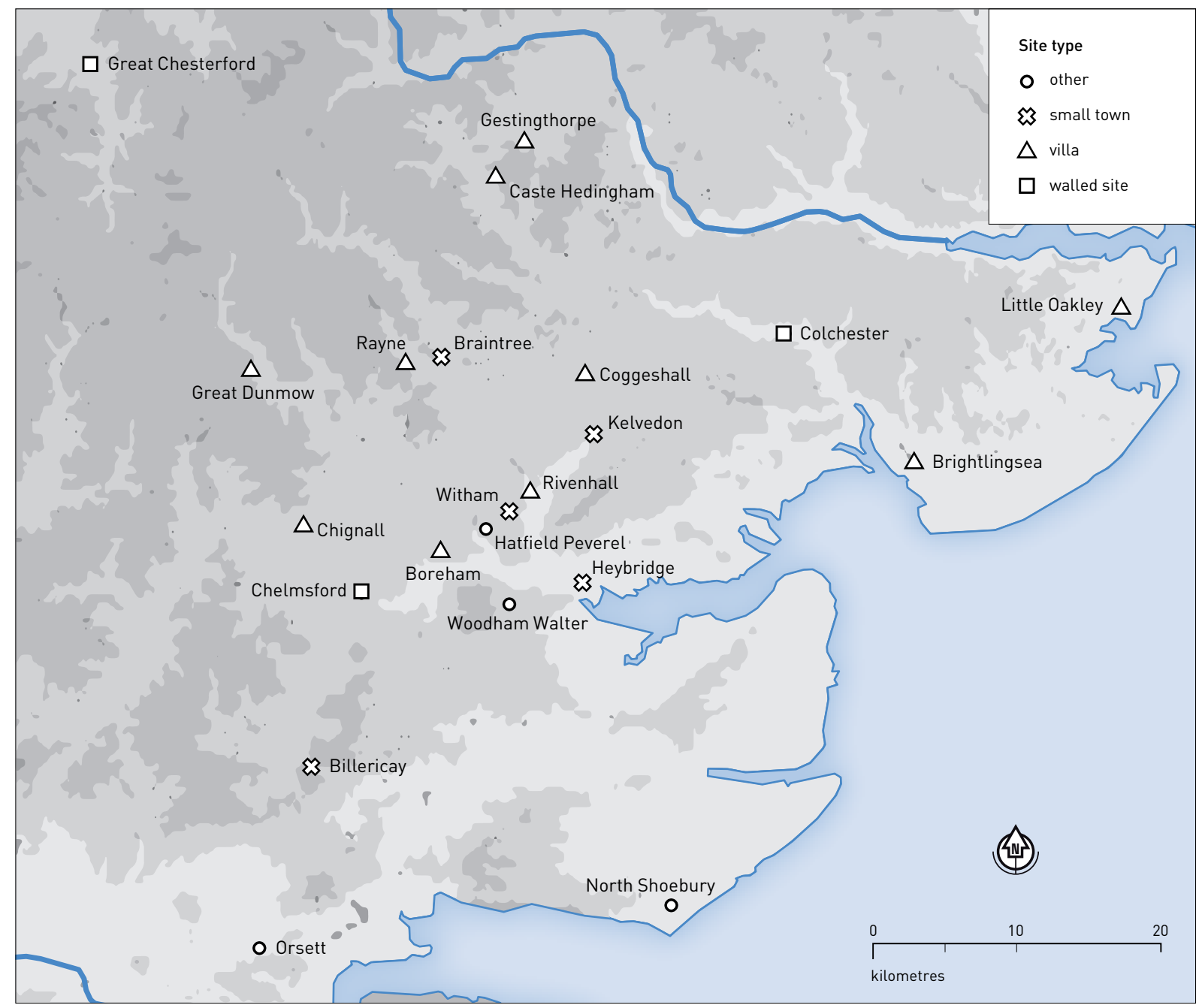

Fig. 6.1. Location map of consumption sites in Essex with ‘Rhenish’ wares and terra sigillata pottery. Site types after Perring 2002.

In general terms 'Rhenish' wares reached as widely as sigillata, but were always represented by a much thinner scatter. ${ }^{715}$ This hampers the analysis, even in a well-supplied region like Essex. Table 6.1 lists published Essex sites (Fig. 6.1) where 'Rhenish' wares were present and quantified at the site level (number of sherds $\left.{ }^{716}\right)$. Overall the presence of sigillata at these sites tends to be in the order of x50 to x100 times that of 'Rhenish' wares by number of sherds, and even higher if quantified by weight, given the often very thin walls of 'Rhenish' wares as compared to the later sigillata. Even on sites yielding comparatively many 


\begin{tabular}{|c|c|c|c|c|c|c|}
\hline site type & site & CG RW & EG RW & CG TS & EG TS & assemblage size \\
\hline \multirow[t]{2}{*}{ urban } & Colchester & yes & yes (more) & yes & yes & \\
\hline & Chelmsford & $\begin{array}{l}y \text { yes } \\
\text { (more) }\end{array}$ & yes & yes & yes & total $600 \mathrm{~kg}, 45000$ sherds \\
\hline \multirow[t]{7}{*}{$\begin{array}{l}\text { lesser } \\
\text { nucleated }\end{array}$} & $\begin{array}{l}\text { Great } \\
\text { Chesterford }\end{array}$ & no & no & $\begin{array}{l}\text { yes }(88 \% \text { of total } \\
\text { TS) }\end{array}$ & yes (10\% of total TS) & \\
\hline & Braintree & yes & no & yes & yes ("fair proportion") & $\begin{array}{l}3 \text { reports: } 1100 \text { sherds, } 11000 \mathrm{~g} ; 800 \\
\text { sherds, } 10500 \text { g; } 3996 \text { sherds, } 54385 \text { g }\end{array}$ \\
\hline & Kelvedon & no & no & $\begin{array}{l}\text { yes (relatively little } \\
\text { 2nd century) }\end{array}$ & $\begin{array}{l}\text { yes (less than } 5 \% \\
\text { exceptionally little) }\end{array}$ & \\
\hline & $\begin{array}{l}\text { Great } \\
\text { Dunmow }\end{array}$ & no & no & yes & $\begin{array}{l}\text { yes (low proportion; less than } \\
10 \% \text { of Antonine TS) }\end{array}$ & \\
\hline & Billericay & yes & no & yes (majority) & yes (little) & \\
\hline & $\begin{array}{l}\text { Ivy Chimneys, } \\
\text { Witham }\end{array}$ & yes & yes (more) & yes & $\begin{array}{l}\text { yes (exceptionally much; } \\
\text { esp. Trier) }\end{array}$ & $\begin{array}{l}\text { total: } 438 \text { EVE; Group 4: } 4036 \mathrm{~g}, 3.27 \\
\text { EVE; Group 10: } 37445 \mathrm{~g}, 47.61 \mathrm{EVE} \\
\text { Group 11: } 25790 \mathrm{~g}, 29.15 \mathrm{EVE}\end{array}$ \\
\hline & Heybridge & yes & no & yes & $\begin{array}{l}\text { yes (exceptionally much; } 30 \% \\
\text { of Antonine TS) }\end{array}$ & $>181 \mathrm{~kg} ; 15300$ sherds \\
\hline \multirow[t]{8}{*}{ rural: villa } & Chignall & yes & yes (slightly more) & yes & yes $(9,8 \%$ of total weight TS) & $\begin{array}{l}\text { total Iron Age and Roman: } 245.5 \mathrm{~kg}, 23000 \\
\text { sherds (TS total } 3190 \mathrm{~g} \text {; RW total } 45 \mathrm{~g} \text { ) }\end{array}$ \\
\hline & Boreham & no (?) & no (?) & yes & yes & \\
\hline & Gestingthorpe & yes & yes & yes & yes (low proportion) & \\
\hline & Nazeingbury & no & no & yes & no & \\
\hline & Rivenhall & yes & yes & yes & yes & $\begin{array}{l}\text { Period 3A: } 5890 \mathrm{~g}, 713 \text { sherds, } \\
8.00 \text { EVE }\end{array}$ \\
\hline & Coggeshall & yes & no & yes & yes (late Antonine) & \\
\hline & Brightlingsea & no & $\begin{array}{lll}1 \\
\text { no }\end{array}$ & yes & $?$ & 1139 sherds, $18994 \mathrm{~g}, 21.83 \mathrm{EVE}$ \\
\hline & Little Oakley & no (?) & no (?) & yes & yes & \\
\hline \multirow{6}{*}{$\begin{array}{l}\text { rural: } \\
\text { lower } \\
\text { status }\end{array}$} & Orsett & no & no & yes & yes (some) & \\
\hline & $\begin{array}{l}\text { Hatfield } \\
\text { Peverel }\end{array}$ & no & $\begin{array}{lll}\cdots \\
\text { no }\end{array}$ & yes (?) & $?$ & \\
\hline & Rayne & no & $\begin{array}{l}\text { yes (labelled as Trier } \\
\text { colour-coated) }\end{array}$ & yes & $\begin{array}{l}\text { yes (little: } 4,6 \% \text { of total } \\
\text { weight, } 15 \% \text { EVE) }\end{array}$ & 18312 sherds, $178054 \mathrm{~g}, 99.04$ EVE \\
\hline & $\begin{array}{l}\text { Castle } \\
\text { Hedingham }\end{array}$ & no & yes (1 sherd) & yes (2 pieces) & yes (more than CG, 6 pieces) & $>12 \mathrm{~kg}, 1192$ sherds \\
\hline & Tilbury & $\begin{array}{lll}0 \\
\text { no }\end{array}$ & no & yes ( 2 sherds) & yes ( 1 sherd) & \\
\hline & $\begin{array}{l}\text { North } \\
\text { Shoebury }\end{array}$ & $?$ & $?$ & yes & $?$ & \\
\hline
\end{tabular}

Table: 6.2. Presence and absence of Central (CG) and East Gaulish (EG) sigillata (TS) and 'Rhenish' wares (RW) at published sites with appropriate chronological range in Essex. Data based on site reports listed in Perring 2002, 73-79.

'Rhenish' wares, patterning within and between individual contexts is tenuous. For example, the most substantial quantified group at Ivy Chimneys (Group 10) counted 37445g/47.61 EVE pottery overall, of which only $28 \mathrm{~g}$ Central Gaulish and 23g/0.09 EVE East Gaulish 'Rhenish' wares. ${ }^{717}$

One possible way round this would be to plot presences and absences of 'Rhenish' wares at site level (Central and/or East Gaulish sigillata is present on all sites). The results are represented in Table 6.2. However, the pattern is not that robust either: in the case of a thinly distributed product like 'Rhenish' wares, large assemblage sizes are needed to assure a representative pattern. Since most sites under study did not yield samples of

717 Turner 1999. 
sufficient size, arguments based on absence are statistically unwarranted. Hence the most suitable strategy might be to select individual instances - sites or contexts - of sufficient sample size worth exploring. The reverse side of this strategy, however, is the limited scope for extrapolating to more general patterns or comparisons.

Before continuing, the limits of the data, and by extension of the approach adopted in this book, need to be emphasized. The general methodological principle of this research is to analyse how a 'single' object is defined in different practices. For production, for instance, sigillata was defined as different from other pots both in the practice of clay fetching and in that of firing; and analysis of the production sequences could access these definitions. For consumption, however, various fields of practice can be theoretically distinguished, but are more difficult to disentangle empirically. This is in large part due to the nature and resolution of the evidence: assemblages are mixed, their formation processes complex, and their chronology often uncertain. Whereas the proverbial single potsherd can tell a whole story of production, it often only speaks to 'presence' in consumption contexts.

Despite these methodological difficulties, a general claim supported by the evidence of the Essex sites is that sigillata and 'Rhenish' wares were not mutually exclusive in consumption practices. This holds true both on the fine-grained level of individual contexts and on the coarser scale of site-wide quantifications by phase. For example the fabric incidence by ceramic phase at Chelmsford shows that the quantitative peak for both products coincides in phase 4 (AD 160/75-200/10) ${ }^{718}$ : not only did one product not replace the other, the more sigillata there was at the site level, the more 'Rhenish' ware. This positive correlation is probably due to shared supply mechanisms.

But does this correlation hold true across contexts at a single site? At the presumed 'religious complex' at Ivy Chimneys (Witham), for example, two quantified groups containing 'Rhenish' wares are of sufficient size to allow for this kind of analysis. ${ }^{719}$ Group 11 (F3321; 29.15 EVE) filled a depression and was dated to the mid fourth century. ${ }^{720}$ It contained, among others, Nene Valley colour-coated wares $(0.6 \%$ weight), East-Gaulish 'Rhenish' wares (0.07\% weight) and East Gaulish sigillata (0.09\% weight). Both by weight and EVE, the ratio of 'Rhenish' ware to sigillata is higher than the overall signature for the site. The reverse is true for Group 10 (F2409; 47.61 EVE), a depression in which a font was based, yielding Central and East Gaulish 'Rhenish' wares and sigillata, and Nene Valley colour-coats. ${ }^{721}$ Hence on the level of individual contexts, there often is an inverse relation between the representation of 'Rhenish' wares and sigillata - in contrast to supply levels to individual sites. Even allowing for issues of taphonomy and differential deposition, this may suggest that both products were catering for different contexts and actions.

\section{2 .2 'RHENISH' WARES: CREATING TIES}

During the phase of experimentation in the early 2nd century some one-off sigillata forms were produced at Lezoux but were not exported. ${ }^{722}$ Once the sigillata production sequence became standardized, however, the entire repertoire was exported and generally reached all kinds of sites, be it in different proportions. ${ }^{723}$ What about its 'Other', Central Gaulish 'Rhenish' wares? For the redistribution hub at London, it was observed that ' $[\mathrm{t}] \mathrm{he}$ large number of Lezoux folded beakers at New Fresh Wharf is particularly significant as the type is comparatively rare in museum collections in Central and East France'. ${ }^{724}$ This points towards a model where 'specials' were preferentially targeted towards long-distance trade; in general accordance with Picon' ${ }^{725}$ model for sigillata where long-distance trade was the primary incen-

\footnotetext{
718 Going 1987, 107.

719 Turner 1999.

720 Turner 1999, 168.

721 Turner 1999, 167.

722 See section 3.4.2.
}

723 Willis 2005 for supply to Britain by site type.

724 Miller/Schofield/Rhodes 1986, 119, referring to Symonds, pers. comm.

725 Picon 2002a. 
tive for increased investment in production. As sigillata's 'Other', Central Gaulish 'Rhenish' wares were drawn into a similar model of 'marketing' for long-distance destinations.

For East Gaulish 'Rhenish' wares, however, a different pattern of destination can be discerned. In 1914 Oelmann already observed for 3rd century Trier 'Rhenish' wares that '[d]urch Töpfereifunde ist sie bisher nur in Trier festgestellt, und zwar findet sie sich hier in ihrer glänzendsten entwicklung, in Gefäßen von außergewöhnlicher Größe und mit einem Reichtum der Dekoration, besonders in Weißbarbotine und buntem Applikenrelief. ${ }^{726}$ This preferential distribution of the most elaborate, highly decorated vessels in and around Trier itself suggests a model of targeted destination where long-distance trade was not a trigger for higher investment in production. Moreover, the difference between these elaborately decorated vessels, often of special forms (e.g. crater Thomas 6), and their 'normal' counterparts (largely dominated by form Niederbieber 33), was much larger - both quantitatively and qualitatively - than that between 'more' or 'less' elaborate sigillata or Central Gaulish 'Rhenish' wares. The patterning of the 'specials' is paralleled by the general distribution pattern of Trier motto beakers, which has a clear regional focus (Figs 5.7 and 5.8). These observations fit well with the above description of how local contingencies were defining for Trier 'Rhenish' ware production. If definition of these 'rooted' products was dependent upon locally salient associations (e.g. the puns on Trier motto beakers), then it should cause no surprise that especially elaborate examples that had these associations writ large were primarily targeted towards local consumption.

As a result, the thin scatter of 'Rhenish' wares is more than an analytical hurdle; it has interpretative leverage too. 'Rhenish' wares' reliance on local ties in production created a distribution pattern skewed towards its immediate locality of production. The resulting thin scatter of 'Rhenish' ware pots in Britain in turn itself set certain conditions for how it could be consumed. This is material culture at work as history-maker! Because there were few of them, 'Rhenish' ware pots would have been more easily associated or contrasted with other products in consumption, rather than other 'Rhenish' ware vessels. Moreover, the tall and irregular shapes of (especially Trier, to a lesser extent Central Gaulish) 'Rhenish' wares (e.g. jugs, in contrast to sigillata) would have made stacking difficult, and would have necessitated more individual criteria of storage and use for 'Rhenish' ware vessels. Think about how one teapot or one special beer glass both takes up more space and is more visible in your kitchen cupboard than six neatly stacked plates.

Is it possible to characterize these general possibilities of use of 'Rhenish' wares in more detail? At Billericay no quantification has been reported, but a single context warrants attention by its qualitative features: the fill of a deep, circular pit which possibly functioned as a well contained a Central Gaulish 'Rhenish' ware beaker (Bet 310). ${ }^{727}$ The beaker was decorated with a barbotine scroll and leaf pattern, and its sherds - with joints between the different fill layers - were significantly less abraded than other pottery in the same context. It is difficult to say whether the specifics of this beaker (elaborately decorated, possibly intentionally broken?) had any relation with a (ritual) closure of the well; and it has to be noted that other wells at the site contained sigillata and colour-coated wares but no 'Rhenish' wares. But a similar case can be cited from Neatham (Hampshire), where two pits (14 and 16) contained complete East Gaulish 'Rhenish' ware motto beakers in deposits associated with the beginning and ending of the use life of a well. ${ }^{728}$ At the same site two (almost) complete folded 'Rhenish' ware beakers were found in Wells 5 and 8 respectively.

At the Rivenhall 'villa site' a single but admittedly small (5890 g, 713 sherds, 8.00 EVE) stratified group (AD 190-220/230) was quantified, with a high overall ratio between 'Rhenish' wares (all origins: $3.50 \% \mathrm{EVE}$ ) and sigillata (all origins: 8.25\% EVE). Moreover, for the same group an exceptionally large number of beakers were recorded. ${ }^{729}$ Beaker forms spanned several fabrics - including 'Rhenish' wares

726 Oelmann 1914, 36-37; Harris 1986.

727 Rudling 1990: Group 8, Trench A, Context 53.

728 Millett/Graham 1986, 72-75. Harris 1986 for other 'reli- gious' contexts of 'Rhenish' ware deposition in Britain and on the Continent.

729 Rodwell/Rodwell 1985. 
- but were dominated (80\%) by British colour-coated fabrics. This hints at a pattern observed for other sites and contexts too, where colour-coated wares stand in the same relation to sigillata as 'Rhenish' wares, and can thus be assumed to have catered for the same consumption practices as 'Rhenish' wares. ${ }^{730}$ Unsurprisingly, form seems to have been the decisive criterion in shaping ' $R$ henish' wares' possibilities for use, and these forms were geared towards drinking practices, as were colour-coated wares.

The Antonine cremation grave assemblages from Great Dunmow further endorse this relation of colour-coated wares to sigillata. ${ }^{731}$ Colour-coated wares made up $35,1 \%$ of the grave assemblages, a percentage similar to the 2nd century funerary assemblage from Skeleton Green, but much higher than contemporary non-funerary samples. ${ }^{732}$ A slightly later Gravel Pit (857; AD 190-240) at the site yielded only 9,8\% EVE colour-coats. Hence colour-coats were clearly targeted at this specific (funerary) field of practice. Even though we cannot account for the absence of 'Rhenish' wares in these same contexts ${ }^{733}$, we could tentatively suggest that in theory they would have fitted in with this enactment of colour-coated wares. It follows that this niche of consumption practices was not dependent on 'external' imports, but was in accordance with local practices. The large dominance of beakers within the graves ${ }^{734}$ as well as among the colour-coated repertoires hints at a specific role for drinking within these practices. Nevertheless, the 'external' imports - 'Rhenish' wares and continental colour-coated wares - had indirectly contributed by shaping the development of the British colour-coated industries.

Finally, Willis noted an association between what he calls 'black sigillata' - merging sigillata forms executed in black and Central Gaulish 'Rhenish' wares - and structured deposits. ${ }^{735}$ This could indicate an early development of an association between products 'Other' to sigillata (that were clearly not sigillata) and ritual, formalized kinds of actions.

However tenuous the precise characterization of these examples remains, all of them fit a description of 'formalized' or 'focused' action - whether 'funerary', 'ritual', or 'religious'. I would tentatively suggest that these kinds of action were aimed at actively creating ties and relations. This could be played out in different ways, in relation to a community, to other places, to an event, to the otherworldly, to the deceased, etc. These fields of practice required a 'thing' that afforded, reinforced, or even triggered explicit, personalized relations. Both colour-coated and 'Rhenish' wares seem to have matched up to that requirement.

Why? In production and distribution ${ }^{736}$, these products relied heavily on local contingencies. This 'rooted' definition facilitated a process of reproduction and local adjustment of skills and know-how. ${ }^{737}$ The argument can now hypothetically be extended to include the possibilities for consumption and use. Relatively few products reached Britain, resulting in a thin scatter, which made 'Rhenish' ware pots stand out. At the same time, emphasis on local ties during production created a definition of these products that was amenable to practices of consumption aiming at the creation of explicit links and entanglements. How things are used is thus decided through adjustment between a thing's trajectory (and the kinds of action it affords), and a context's field of practice (and the kind of action it requires).

Finally, the specificity of the kinds of action for which 'Rhenish' wares and/or colour-coated wares were preferentially selected curtailed their economic possibilities: their niche was circumscribed, and could not easily be expanded. Even though actions 'creating ties' could occur on any site, it seems rea-

730 Cf. relation between 'Rhenish' wares and colour-coated wares in production (Chapter 5).

731 Wickenden 1988.

732 Wickenden 1988, 22.

733 Possible supply issues due to Great Dunmow's western location; chronology rules out East Gaulish products.

$73473 \%$ of the Great Dunmow cremations contained drinking implements (Wickenden 1988, 22). Pitts 2005, 2007a,
2010 for earlier periods.

735 Willis 2005, 6.5.3.

736 Resolution is insufficient to examine whether Central Gaulish 'Rhenish' wares' different definition as sigillata's 'Other' (Chapter 5) in production and distribution had any effect on their possibilities for consumption.

737 See section 6.1.2. 
sonable to posit that this could only ever describe a limited range of a repertoire of action. ${ }^{738}$ This is confirmed by Pollard's observation for Kent that colour-coated and 'Rhenish' wares

'account for less than 4 per cent of quantified assemblages of second and mid-second to mid-third century dates (...), suggesting that the introduction of new pottery styles, and the emergence of the Nene Valley and Central Gaulish 'Rhenish' wares did not occasion an expansion of the market for colourcoated wares'. ${ }^{739}$

For the Essex sites 'Rhenish' and colour-coated wares similarly seem to have occupied an easily saturated consumption niche. For example, even on a site with a strong 'formalized' orientation and a relatively high representation of 'Rhenish' and colour-coated wares like Ivy Chimneys the share of contexts marked by this kind of assemblage remains limited.

\section{2 .3 S IGILLATA: THE J OKER}

Sigillata was spread more densely and in greater numbers across sites in present-day Essex than 'Rhenish' wares. ${ }^{740}$ Following a retrospective template of material culture, causal explanations for this wide spread are sought with external actors. With regard to consumption, sigillata's archaeological pattern is attributed to a generalized 'taste for' these bright red shiny pots. Sigillata pots' distinctive visual (shiny red appearance versus a majority of greyish or buff wares) and economic (long-distance origin) characteristics are often implicitly bound up with presumed associations of 'Romanness': people in Britain 'desired' these pots because they reflected a 'Roman' identity. ${ }^{741}$ But was sigillata really coming in with associations of 'Romanness' or 'long-distance origins'?

Because there were always more than a couple of sigillata pots in any one context, this product is likely to have been conceptualized in 'sets', especially as functional or formal services. ${ }^{72}$ As a result, sigillata was more amenable to internal differentiation, whether based on form, size, or decoration. Even small assemblages in Essex (e.g. Billericay) show a wide range of sigillata forms ${ }^{743}$, and hence at least one axis for significant internal differentiation in consumption practices, with different settings requiring different shapes. Different traits could be emphasized (e.g. colour, form, decoration) in different contexts, entailing flexibility in use, and the potential of being inserted in many different kinds of practice. Differences between sigillata assemblages across contexts have long been noted, but the historical question has always focused on meaning: who selected this decoration and what did it stand for?, why were these shapes preferred in this context? The historical explanation is then, again, bound to reside in conscious, selecting, meaning-giving agents. Instead, following the historical trajectory of sigillata lends an insight to a more primary, generative role of sigillata 'before meaning': how these pots could be consumed across a wide range of contexts. Again, the answer lies in sigillata's definition as a category, defined by a package of traits, which could feature as axes of differentiation, and made sigillata a flexible object of consumption.

More specifically, sigillata was not excluded from those fields marked by the creation of ties, but it was not preferentially selected for these either. For example at the small rural site at Rayne curated South-Gaulish sigillata in 'unusually good condition' featured in 'grave shaped pits' dated to the later 2nd century and identified as 'ritual' contexts. ${ }^{744}$ At Great Dunmow sigillata featured equally prominently in funerary assemblages and in the context of a gravel pit, both of a same 2 nd century date. ${ }^{745}$ Some of the

\footnotetext{
738 Cf. Felski 1999, 27, echoing Heidegger 1977.

739 Pollard 1988, 82.

740 Sometimes outnumbered by colour-coated wares.

741 Gosden 2005, 198-199, based on Miller 2002b (below). Also e.g. Woolf 1998, $190 \mathrm{ff}$.

742 Monteil 2012; Vernhet 1976; Willis 2005.
}

\footnotetext{
743 Rudling 1990.

744 Smoothy 1989, 15. One fragment of adult human skull was found; the remainder of the expected bone assemblages had possibly decayed.

745 Wickenden 1988.
} 


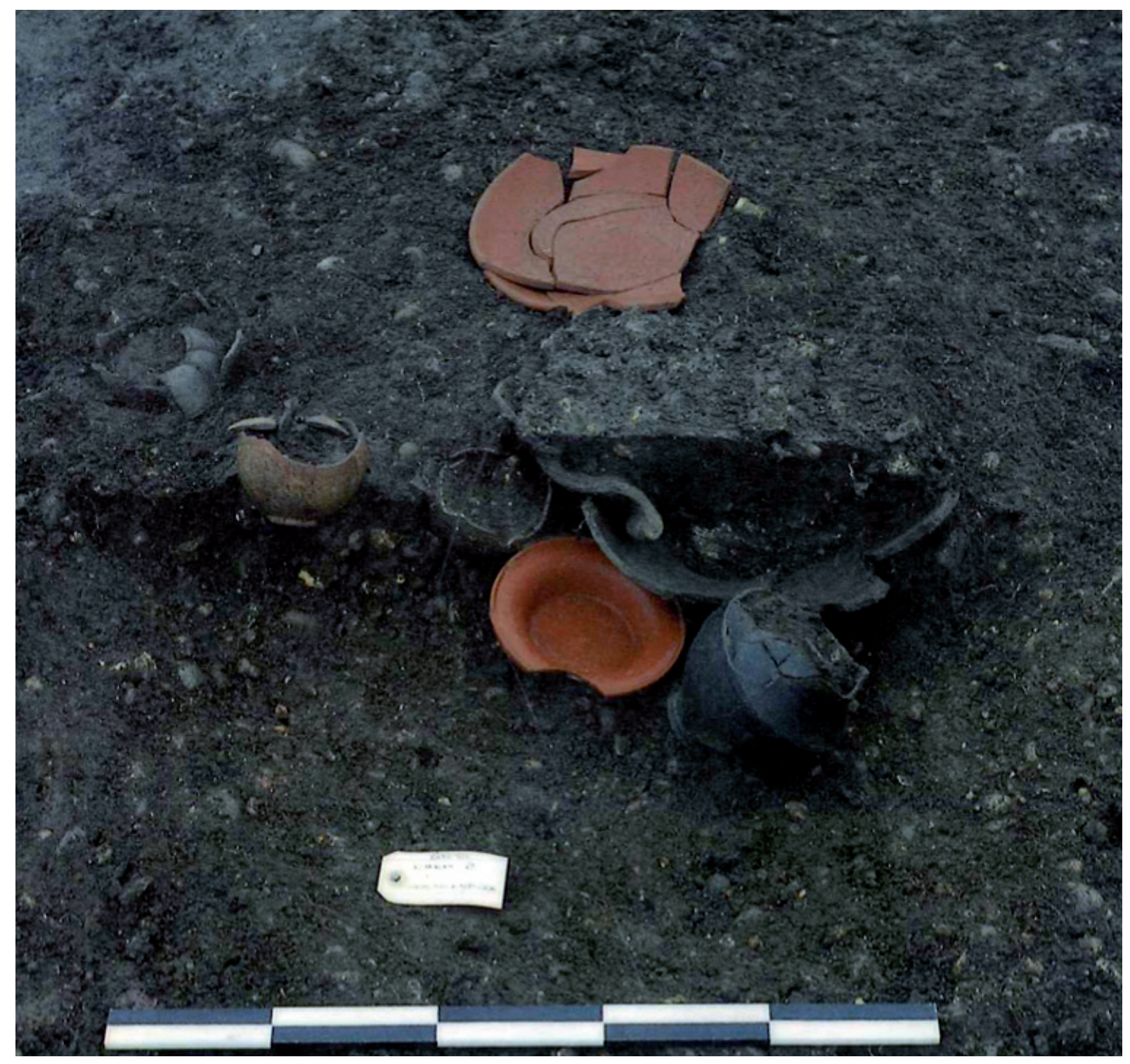

Fig. 6.2. Great Dunmow, cremation burial with fractured terra sigillata plate at front (second half 2 nd century AD). From Wickenden 1988, 17, Plate 2 (with permission).

sigillata fragments in the burials show signs of deliberate fractures (Fig. 6.2), and not all of the pieces appear to have been buried. The publication speaks of 'killing' ${ }^{746}$ the vessels, but 'fragmentation' ${ }^{747}$ might be a better term to describe the creation of relations as pieces of the former 'whole' could be carried away by participants. In other words, this practice aimed at forging ties, with the deceased, with the participants in the actions; and sigillata was insertable in the associated practices, but not preferentially selected for them. More generally Willis has shown for Britain that sigillata was not geared towards use in ritual contexts or around temples, but not banned from these situations either. ${ }^{748}$

Hence the suggestion that sigillata functioned as something of a 'joker' that could be inserted in various contexts and actions, and support those actions rather than impose its own specificities onto them. ${ }^{749}$

746 Wickenden 1988, 22-23.

747 Sensu Chapman 2000.

748 Willis 1998, 2005, 7.2.6. Cool/Leary 2012 for more detail on the possible (non-)uses of sigillata in burial rites in Britain.

749 Hetherington/Lee 2000, after Michel Serres. But, in contrast to a joker, sigillata was among the best-represented 'cards' (in casu fine wares). 
How did this general possibility of use feed into sigillata's definition as traced above through production and distribution? As a category, sigillata was clearly bounded, and defined by a limited and consistent package of traits whose instantiations could be compared one to another. The package of traits facilitated sigillata's flexibility across different contexts: different traits could be used as defining parameters (form, decoration, etc.). But sigillata's boundedness - how it was kept apart from other products, and from its contingencies of production and distribution - had its role to play too. It made sigillata into a thing that was void of ties, whose specific relations and contingencies did not prefigure its biography, and which, as a consequence, was amenable to being used for many different kinds of actions. Instead of coming in with 'special' associations, for instance to Roman culture or far-flung origins, sigillata entered consumption contexts in Britain without ties.

Insertion of a joker in a card game can either confirm the structure of the game or radically alter it. The limited resolution of the evidence makes it hard to further specify how the use of sigillata as a 'joker' in consumption could trigger unexpected change as well as stasis. At Orsett, for example, decorated sigillata sherds (Central and East (Rheinzabern) Gaulish) were abnormally well-represented in the later 2nd century AD (both in relation to other sites and to other phases at Orsett), and hunt scenes seem to have been preferentially selected for. ${ }^{750}$ This hints at an association with the hunt scenes that were much more commonly depicted (in barbotine instead of moulded) on colour-coated beakers (and, less often, on 'Rhenish' wares). Was sigillata locally appropriated, and was its flexibility exploited to reinforce preexisting traditions?

Unfortunately no 'Rhenish' wares and very few colour-coated wares were reported. Here a combination of small sample size and (as a result) lack of full publication and quantification makes it impossible to follow through the relations on this micro-level. So even though the publication's assumption that the sigillata hunt scenes represented 'local taste ${ }^{751}$ is to be discredited on theoretical grounds, resolution is insufficient to come up with an alternative reading.

\subsection{THE MAKING OF AN ARCHAEOLOGICAL PATTERN}

The archaeological pattern of terra sigillata, then, was not just the result of the traders selling it, or the people consuming it. Terra sigillata made its own archaeological pattern. As a category, sigillata came with strict parameters for (re)production. It facilitated comparison, and was thus able to impose rigid standards and limited variability on attempts at reproduction. As a consequence, production sites of sigillata according to the Lezoux template of a category were few, resulting in a centralized production landscape. The production landscape of 3rd century East Gaulish sigillata, which were not defined in a similar way, instead consisted of a larger number of smaller production centres. Sigillata's definition as a category also shaped its archaeological pattern of a wide and dense presence on consumption sites. The different traits in its defining package provided axes of differentiation that could be called upon to suit the specifications of different consumption contexts. In addition to this flexibility, sigillata's boundedness meant that it did not rely on or impose prior associations. In sum, the archaeological pattern of sigillata does not just tell us about the activities and choices of investors, traders, and consumers. It also tells us about sigillata's role as history maker - how it shaped the possibilities for its own trajectory, including reproduction and consumption. This role preceded meaning in that sigillata created its conditions for action, but did not decide how these conditions would actually be filled in. As a category, it could be inserted in different kinds of practices 'before meaning' was actually attributed to it.

\footnotetext{
750 Carter 1998.

751 Carter 1998, 94.
} 
We can observe similar processes in the modern world. Miller has analysed how Coca-Cola is appropriated in Trinidad as a local 'black sweet drink' that found its way within the existing practices. ${ }^{752}$ But while Miller uses this example to nuance the degree to which multinational concerns dictate the possibilities for using their products ${ }^{73}$ - Coca-Cola does not restructure Trinidadian society or impose an 'Americanised' identity - this argument can be turned around to illustrate the success that allowed CocaCola to become 'globally' taken for granted, albeit in very different ways and reflecting a wide range of values. And this success resides in part in its definition as a category, like sigillata. A similar claim has been made with regard to petrol stations as 'global entities', whose 'very standardisation enables variation and heterogeneity of using the place'. ${ }^{754}$ And such an argument would equally suit Apple computers: the more clearly defined they get (in terms of design, software package, applications, etc.), the more seamlessly they are inserted in and appropriated by different niches, from the creative industry over business to education. This contrasts with the earlier, more fuzzily defined Apple products that catered for limited niches such as 'technology adepts' and 'creative professionals'.

But where does this leave the traditional historical narratives accounting for terra sigillata consumption by reference to its associations with 'Romanness' or 'Roman identity'? The creation and maintenance of sigillata as a category had a range of consequences: accountability, measurement, competition, difficult reproduction (and as a result centralization), possible insertion in various fields of practice. These facilitated a particular kind of power ${ }^{755}$, centralized but reaching widely, homogenizing material ambiances but not dictating their semantic relations. Conversely, the creation and maintenance of sigillata as a 'category' was also facilitated by exactly such an enactment of power.

Compare this to scientific facts as examples of categories in our contemporary world. Once created, verified, and stabilized, scientific facts are defined by the 'either/or' parameters that are defining of categories: they do not allow for grey zones or ambiguity in their identification and implementation. These characteristics allow scientific facts to travel widely (scientific laws hold sway over much of the world today) but to remain centralized (with a limited number of laboratories and institutes controlling definition of these facts). A category and its consequences are not neutral arrangements, but perpetuate a particular power structure; in the case of scientific laws, an 'empire of science'. ${ }^{756}$

Woolf commented that ' $[\mathrm{u}]$ nderstanding the nature of [the] linkage between empire and culture is the key to understanding the processes usually termed Romanization' ${ }^{757}$ Even though the power structure of the Roman empire cannot be described in the same detail as the various processes and actors at work in modern scientific practice, we can begin to describe the nature of the flows of things resulting from and stabilizing that power structure. In particular, following through the distribution, reproduction, and consumption of sigillata has described exactly the kind of trajectory tied into an 'empire-like' structure. To be clear, this points to a specific configuration - arising from contingent processes such as the category formation of sigillata at Lezoux - and not to an underlying 'Machiavellian' strategy to accrue power or economic gain. ${ }^{758}$

The 'rooted' definition of (Trier) 'Rhenish' wares in turn created rather different dynamics. ${ }^{759}$ It enabled a sense of place, community, and embodied craftsmanship in production at Trier, and reinforced selective fields of consumption practice in Essex. This in turn helps make sense of the historical processes of the 3rd century AD. By that time, the power structure of the Roman Empire was increasingly depend-

752 Miller 2002b.

753 Cf. de Certeau 1984.

754 Normark 2006, 242.

755 For the relation of some of these consequences (especially accountability and measurement) to power, see Foucault 1975.

756 Latour 1987; Law/Singleton 2005, 335.
757 Woolf 1998, 18

758 Critique of Latour by de Laet/Mol 2000.

759 The distinction between a 'category' and a 'rooted' thing does not map onto that between 'object' and 'thing' derived from Heidegger (Gosden 2004, 35-38; Harman 2002): the former denote relational constellations, the latter degrees of 'in-place-ness'. 
ent on the personal ties of the emperor himself. During the last quarter of the 3rd century, Trier became the capital of the Gaulish part of the Later Empire, where the emperor and his court resided. ${ }^{760}$ It is thus no surprise to see the rooted constellation of 'Rhenish' wares coincide with a locality that epitomised the new, increasingly personalised, and selectively connected power structure. At the same time, the homogeneous material culture of the Western Roman provinces gradually receded to the background, making way for more regional differentiation in production and consumption. 'Rhenish' wares actively contributed to this pattern, by promoting specific kinds of consumption practices in which local and personalized ties were writ large.

The non-retrospective account of reproduction and consumption sketched in this chapter is thus 'before meaning' in two ways. First, it discusses the structuring role of sigillata and 'Rhenish' wares in creating conditions by which people in the past could give meaning to the pots they consumed. In the case of sigillata, this attribution of meaning was left virtually blank, whereas it was more narrowly steered by 'Rhenish' wares. Second, the account presented here is also 'before meaning' in that it precedes the meaning archaeologists read into a certain archaeological pattern. Whether the wide and dense spread of sigillata in Britain reflects aspiration to a 'Roman identity' or not, it did help create a material homogeneity and a recognisability despite (or through) a wide range of possible identities and meanings ${ }^{761}$

760 Wightman 1970

761 Pitts 2008; Pitts/Verluys 2015 for an exploration of the tension between homogeneity and heterogeneity through the lens of globalisation theory. 